\title{
Retrato, pessoa e imagem: o universo fotográfico de Madalena Schwartz
}

\section{Marco Antonio Teixeira Conçalves}

- Universidade Federal do Rio de Janeiro / Rio de Janeiro, RJ, Brasil

\marco@ifcs.ufri.br

\section{RESUMO}

Este artigo empreende uma análise da obra de Madalena Schwartz, fotógrafa húngara radicada em São Paulo desde a década de 1960, responsável por constituir um acervo visual do Brasil no final do século xx por meio do retrato. A partir de sua obra, exploro o significado do retrato na construção do imaginário moderno e seus rebatimentos nas discussões conceituais sobre imagem, fisicalidade, pessoa, semelhança e indivíduo na antropologia. A reflexão que empreendo sobre os retratos de Madalena Schwartz segue conceitualmente a virada fenomenológica na formulação teórica sobre a fotografia nas ciências sociais, que privilegia mais o nível experiencial do que o semiótico. O retrato, assim, envolve engajamento e experiência, sendo constituído por meio de relações sociais. Nesse sentido, o retrato é tomado enquanto materialização da relação entre o fotógrafo e o fotografado.
PALAVRAS-CHAVE

Retrato, Fotografia, Pessoa, Imagem, Indivíduo, Madalena Schwartz. 
Este artigo empreende uma análise da obra de Madalena Schwartz ${ }^{1}$ explorando o significado do retrato na construção do imaginário visual moderno e seus rebatimentos nas discussões conceituais sobre imagem, fisicalidade, pessoa, semelhança e indivíduo na antropologia. MS foi uma importante fotógrafa, radicada em São Paulo, que atuou nas décadas de 1970 e 1980 produzindo uma obra materializada em mais de 16 mil fotogramas, em que retrata pessoas anônimas, artistas, políticos, personalidades, escritores, constituindo um acervo visual do Brasil no final do século xx por meio do retrato. A partir de uma incursão de pesquisa em seu acervo no Instituto Moreira Salles (contatos, sequências, digitalizações, ampliações, livros), objetivo aqui compreender a composição conceitual do retrato engendrado por MS na sua prática imagética.

A reflexão que empreendo sobre os retratos de MS segue conceitualmente a virada fenomenológica na formulação teórica sobre a fotografia nas ciências sociais, que privilegia mais o nível experiencial do que o semiótico (cf. Edwards, 2002: 67; Edwards, 2011: 185; Pinney, 2000; Head, 2009). O retrato envolve engajamento e experiência, sendo constituído por meio de relações sociais (cf. Edwards, 2012: 228). O conceito de corpothetics formulado por Pinney permite empreender uma reflexão sobre o retrato como da ordem do sensório, da experiência, do corporal, uma vez que corpothetics implica a não separação entre imagem e observador (Pinney, 2004: 8, 19, 194). Head (2009: 37-48) aprofunda o problema da potência da imagem fotográfica, da fotografia como fetiche e encantamento e, consequentemente, seu poder de afetar, uma vez que institui e narra uma relação. É nesse sentido que este artigo aborda o retrato: enquanto a materialização da relação entre o fotógrafo e o fotografado, como o efeito de "translação da fotografia abstrata em retrato" (Edwards, 2002: 69).

O retrato, ao processar o trânsito do humano para a imagem, impulsiona uma reflexão sobre a noção de pessoa. Realiza, deliberadamente, a encorporação de uma pessoa a uma imagem. Mauss (2001: 104) aponta que "o retrato está para a pessoa assim como a parte para o todo". Levy-Bruhl (1910: 38, 56; 1922: 38), levando mais adiante a reflexão maussiana, nos diz que, "uma vez que a imagem é o modelo, a imagem é parte do indivíduo e o indivíduo, ele mesmo, é imagem". Concluiu, portanto, que, se o retrato é da mesma ordem de seu modelo, ele é, por definição, "essencialmente místico". Nesse sentido, o retrato possibilita, simultaneamente, uma transcrição e uma transfiguraçãoª : a transcrição nos reenvia à sua fundamentação indiciática, responsável por produzir sua "mística"; a transfiguração aprofunda sua potencialidade abstrata, sendo o que permite evocar uma narração.

Desse modo, o retrato, enquanto gênero, esteve sempre vinculado à biografia do retratado, relacionando de uma só vez história de vida e cultura. O desafio daquele que compõe conceitualmente o retrato é o de condensar em uma pessoa (que é o seu material) elementos que possam compor informações sobre sua vida
1 Doravante referida como MS Agradeço ao coordenador de Fotografia do Instituto Moreira Salles, Sergio Burgi, à Virgínia Albertini e à Raquel de Rezende Miranda pelo acesso e orientação no Acervo Fotográfico de Madalena Schwartz. A maioria das fotos de MS que são referidas neste artigo podem ser vistas no site http:// www.ims.com.br/ims/explore/ artista/madalena-schwartz/obras; http://fotografia.ims.com.br/ sites/\#1479906867191_7. 
e seu mundo. O retrato é, na verdade, "uma pequena narrativa" sobre uma pessoa que se liga à "grande narrativa" cultural ou social a partir de um engajamento efetivo com as imagens (cf. Edwards, 2001: 3). Nesse sentido, o retrato não é apenas um processo visual, mas uma percepção fenomenológica que faz a conexão entre o que é visível e outros registros sensíveis, seja da ordem da cognição ou da emoção (cf. Edwards, 2006: 62).

O retrato, ao incorporar, no mais alto grau, o caráter mimético da representação artística, afeta no sentido em que afetar é descrito por Freedberg (1989): aquilo que constitui a essência das imagens, materialidades subjetivadas com potência de transportar valores, sentidos, emoções. Um exemplo revela o sentido de retrato: um célebre professor de história da arte pede a seus alunos que cada um traga para a aula um retrato de sua mãe. Armando-os com estiletes, o professor demanda que cortem os olhos das respectivas mães retratadas. Diante da hesitação dos estudantes em cumprir a ordem, o professor apresenta a problemática relação entre o retrato de uma pessoa e o que representa (cf. Mitchell, 2005: 9). Assim, o retrato é um modo de injetar subjetividade na imagem de uma pessoa ao criar proximidade entre fisicalidade e imagem, fundindo, ou melhor, confundindo imagem e sua representação.

Seguindo essas formulações mais conceituais, problematiza-se o retrato produzido por ms: qual é a ontologia de sua fotografia? Qual é a qualidade da relação entre fotógrafo e fotografado? Como se produz conhecimento por meio de retratos, de imagens? Quando um fotograma torna-se retrato?

Inicio o artigo com uma breve introdução ao retrato e seus problemas, em que seleciono algumas questões conceituais sobre imagem, pessoa, corporalidade que reverberam nas discussões antropológicas contemporâneas e que, ao mesmo tempo, são um guia na leitura da composição do retrato produzido por Ms, baseado nas ideias de transcendência de uma fisicalidade: aceder ao espírito, à alma, a uma essência, penetrar na mente e no mundo do retratado. Constituo uma pequena história da fotografia de ms, procurando apresentar sua gênese, sua prática e suas relações. A seção Conhecendo com uma câmera: fixando e não fixando imagens aborda seu método de fotografar, em que a máquina é o locus, por excelência, do processo de produção do conhecimento na construção de uma imagem que transborda o fotograma fixado em retrato. Fotografando relações, produzindo retratos explora o retrato enquanto produto de relações sociais, configurado pela reciprocidade estabelecida entre fotógrafo e fotografado. Sequências: quando um fotograma se torna retrato ou ox da questão analisa o retrato enquanto um processo que advém da sequência, juntando de uma só vez o individual e o cultural, o texto e o contexto. Concluo com a seção Etnorretrato: 0 a to fotográfico como ato etnográfico, que retoma as principais questões tratadas no texto na direção de uma síntese do significado do retrato na obra de ms. 


\section{O RETRATO E SEUS PROBLEMAS: "FISICALIDADE”, “ESPÍRITO", “ALMA”}

O retrato radicaliza o aspecto índice da fotografia enquanto uma "classe de signos que mantém com sua referência relações que subentendem uma associação física", fazendo parte do "mesmo sistema que as impressões, os sintomas, os traços" (Krauss, 2002: 15). Na acepção de Newhall (2001), o retrato é um dispositivo de compreensão do mundo desde pelo menos o Renascimento: um modo de acessar mundos por meio de individualidades, fisicalidades, fisionomias.

Burckhardt (2000: 51), ao escrever no fim do século XIX, nos diz que o retrato desenvolve-se no sentido de buscar uma semelhança ao apoderar-se daquilo que representa e de ser, num sentido lato, aquilo que ele quer representar. Assim, a episteme do retrato, como demonstra Foucault (2000), produz o sentido próprio da época moderna: quando o humano surge, simultaneamente, como sujeito e objeto da representação.

A transformação de um ser humano em fotografia ou imagem apresenta, desde sempre, um problema para o pensamento ocidental. No século XVII estava já posta uma classificação que estabelecia uma separação entre portrait (relacionado aos humanos), figure (aplicado aos animais) e representation (aplicado aos desenhos de plantas e elementos inorgânicos) (Schneider, 2002: 10-11).

O retrato ocupa, assim, o lugar de fronteira entre a ideia de imagem e imaginação ${ }^{3}$ ao tentar fixar "uma verdade" sobre um sujeito (cf. Tacca, 2005). No retrato, o rosto é uma condensação do mundo, uma espécie de microcosmos do mundo encarnando uma cosmologia (Le Breton, 2010: 28), uma composição imaginativa a partir de uma relação estabelecida, uma criação ativa desencadeada por uma relação em que se transferem para um suporte as qualidades morais, sociais e culturais por meio de uma fisicalidade. A fisionomia humana associa-se, desde então, a temperamentos, humores e emoções (Schneider, 2002: 16).

A busca pela semelhança, não necessariamente fisionômica, leva a escolhas, seleções, observações que permitem uma composição do humano em fotografia enquanto atribuição de individualidade da figura retratada (Hammond, 1920: 71). Escapar da semelhança fisionômica para aceder às características chamadas humanas, "penetrar no espírito" do retratado é o que ambicionam os fotógrafos quando enfatizam o "misterioso" na produção de um portrait (Freund, 1980: 64, 80).

Esse excesso de semelhança entre uma fisicalidade e uma moralidade nos lança em direção ao que pode ser definido como o "efeito mágico do retrato" (Novaes, 2008: 456-459). Tissandier (1876: 70-71), cientista francês, um dos pioneiros na escrita sobre a fotografia e seus processos físico-químicos, nos fornece em 1876 uma interessante reflexão sobre o retrato. Este teria como função tornar o conto fantástico de Hoffman realidade, em que o amante poderia dar à sua amada seu próprio retrato e, com esta imagem em papel, ela poderia contem-
3 A ideia de imaginação é cons titutiva da fotografia, como nos coloca o fotógrafo britânico David Bailey: "É preciso de muita imaginação para ser um bom fotógrafo. Precisa-se menos imaginação para ser pintor, porque o pintor pode simplesmente inventar as coisas. Mas, na fotografia, tudo é da ordem do ordinário e é preciso olhar muito para aprender a ver o ordinário" (Bailey, 1984 apud Acker, 2004: 44). 
plar a imagem do amado. $O$ retrato, assim, seria aquilo que constitui a pessoa no sentido de fixação de uma imagem.

Dessa forma há um consenso entre os fotógrafos de que o portrait é o mais difícil dos gêneros fotográficos, uma vez que implica uma relação e um entendimento do objeto-sujeito fotografado. Desde os primeiros livros sobre fotografia, insiste-se na ideia de que o retrato deve capturar a "alma" do retratado, revelando "o seu entorno, a profundidade de sua mente e seu sentimento, o modo como a sua inteligência trabalha, seu papel social e seu modo de ver a vida" (Maskell, 1912: 167; Holme, 1905). Buscar essa essência do retrato, ou a composição de uma pessoa, reverbera no modo como se constitui a categoria de indivíduo e pessoa ${ }^{4}$ e suas significações no mundo moderno: o retrato é um estado da mente e não propriamente uma fisionomia, uma vez que o observador do retrato alarga sua própria imaginação ao engajar no retrato suas próprias experiências pessoais.

A face, a fisicalidade é justamente o que o retrato quer transcender, superando a "superfície da aparência". A reflexão original de Anthony Guest sobre o retrato em seu livro Art and Camera, publicado originalmente em 1907, coloca o problema da similitude e da semelhança como o desafio do retrato: ultrapassar o que se vê na imagem, o chamado referente real, dando a ver a semelhança, não como imagem, mas como algo da ordem dos afetos (cf. Keating, 2006: 93).

Nesse sentido, há uma associação direta entre fotografia e espírito. A fotografia, ao tornar o invisível visível por meio de seus efeitos físico-químicos, produz em sua materialidade a dimensão do "espírito" do referente. A fotografia conduz, assim, à comunicação entre campos "materiais" e "espirituais", revelando uma nova percepção (cf. Harvey, 2007: 7). Daí mesmo advém sua dupla natureza: um instrumento científico para criar um mundo visível pleno de fisicalidades e, ao mesmo tempo, algo estranho 5 , que pode "evocar a aparência de sombras e associações sobrenaturais" (Harvey, 2007: 7).

Taminiaux (2009: 131) coloca o problema "espectral" do retrato como o paradoxo da fotografia. A identidade espectral tensiona verdade e ilusão, realidade e a parência, sendo o momento em que o "fantasma projeta sua própria luz no mundo visível" (2009: 131). O problema posto pelo retrato não é propriamente a questão da semelhança com a realidade, mas o de colocar em presença algo que não pode ser dito e, assim, "iluminar a essência espiritual da face humana" (Taminiaux, 2009: 137).

O livro de Tassadier identifica o exato momento em que o portrait produz-se enquanto uma "era que tinha sede pela face humana" (1876: 146) ${ }^{6}$. Essa percepção de que o retrato revela através do exterior, da fisicalidade de uma pessoa, a sua interioridade é objeto do livro Fotografia e a alma humana (Sobieszek, 1999), uma incursão ao retrato fotográfico moderno nos últimos 150 anos. Ao propor uma associação entre rosto e espírito humano como partida conceitual, explora
4 Segala (1999: 159, 163) chama a atenção para a questão do individual, do biográfico e suas relações com o retrato: 0 autógrafo, assinatura, no retrato junta definitivamente a pessoa e a imagem retratada, redobrando a imagem em forma escrita no ato de representar o indivíduo e a pessoa.

5 Aqui no sentido de uncanny. Remeto ao conceito produzido por Freud (1976), que se aproxima do efeito da revelação produzido pela fotografia: uma duplicação de nosso olhar, absolutamente natural e banal, sobre o mundo pode fazer irromper algo novo, revelando, literalmente, esse estranhamento sobre o mundo. Veja, por exemplo, esse sentido da fotografia elaborado em dois filmes: Blow-up (Antonioni, 1966) e Janela indiscreta (Hitchcock, 1954). Ver, também, o sentido de fotografia como epifania, aparição e advento proposto conceitualmente por Samain (2012: 157).

6 Deleuze e Guatarri (1987) em um texto em que discutem rostidade, ou facialidade, chegam ao âmago da significação do retrato na modernidade. Demonstram como o rosto foi erguido à potência de evocação do universo ocidental, quando toma a subjetividade como valor extremo de constituição de uma relação social. "A palavra 'pessoa' é de origem latina. Em lugar dela os gregos tinham prósopon, que significa rosto, tal como em latim persona significa o disfarce ou a aparência exterior de um homem [...]" (Hobbes, 1983 cap. xvi: 96 apud Araujo, 2006: 231232). 
suas complexas relações de subversão, representação, interpretação, que ensejam a arte de retratar. O retrato passa a ser a problematização da categoria de indivíduo, uma vez que o indivíduo no retrato é, simultaneamente, contextualizado e descontextualizado, gerado e degenerado, regrado e desregrado (Baker, 1996). Neste contexto, o desafio do retrato é o de causar um efeito imaginativo capaz de transcender a face. A ambição de um retratista é a de apresentar um acesso a outros mundos a partir de um suporte, uma materialidade sensível, a face, que nos permite adentrar nos mundos da mente e da cultura do retratado.

\section{MADALENA SCHWARTZ, UMA PEQUENA HISTÓRIA DE SUA FOTOGRAFIA}

MS nasce em 1921 em Budapeste. Aos 13 anos migra com a família para Buenos Aires, escapando do nazismo na Europa. Em 1960, aos 39 anos, com seu marido e filhos, chega à cidade de São Paulo para tentar a vida no Brasil, quando passa a administrar uma tinturaria localizada em uma região central da capital que, na década de 1970, era reduto de artistas underground paulistanos. MS, morava com a família no célebre edifício Copan, símbolo de uma época de grandes transformações dos costumes e valores paulistanos e muito próximo de sua tinturaria. Seu interesse em fotografia é descrito como obra do acaso. Um de seus filhos recebe um prêmio em dinheiro em um programa de auditório na TV Excelsior e resolve comprar uma câmera. Ms, que até então não fotografava, passa a utilizar esta máquina. Seu despertar pela fotografia Ihe faz frequentar, em 1966, o Foto Cine Club Bandeirantes 7 . Em 1967, participa do primeiro salão de arte fotográfica de São Carlos e ganha menção honrosa. O momento decisivo de sua fotografia surge a partir de um episódio narrado pelo escritor Ignácio Loyola Brandão (Moura e Titan Jr., 2012: 10), que era frequentador de sua tinturaria. MS, sabedora de que ele era editor na editora Abril, resolve mostrar algumas de suas fotos. $O$ escritor fica intrigado com a potência das imagens vindas de uma mulher que ele via "encolhida e tímida atrás do balcão, observando os fregueses com olhos enormes e ansiosos" (Brandão, 1997: 93). Essa relação de mostrar as fotos para Brandão tornou-se corriqueira; a cada semana, MS mostrava mais e mais fotos. Um dia, Brandão resolveu convidá-la para fazer um portrait para a revista Claudia, o que detonou sua carreira: a partir do início dos anos 1970 até o começo dos anos 1980, fotografa incessantemente artistas, escritores, políticos, personalidades que povoam o imaginário sobre o Brasil recente ${ }^{8}$, fotos que deram origem ao seu livro Personae (1997). No começo dos anos 1970, MS fotografa as personagens excêntricas do entorno de sua tinturaria, os frequentadores das boates e dos bares homossexuais e os habitantes do edifício Copan. Produz um fabuloso acervo de fotografias do mundo underground paulistano, como artistas, travestis, transformistas, o que deu origem a seu livro Crisálidas (2012). Nesse momento,
7 Este Club Fotográfico foi, também, um lugar de referências da fotografia na década de 1960 , como Boris Kossoy e Thomas Farkas (Moura e Titan Jr., 2012: 10). Para ver a importância do Club Bandeirantes na produção da fotografia moderna brasileira, cf. Costa e Silva (2004).

8 Fotografou, entre outros: atores: Walmor Chagas, Paulo Autran, Dercy Gonçalves, Ruth de Souza, Irene Ravache, Zezé Motta, Raul Cortez, Bibi Ferreira, Dina Sfat, Dzi Croquetes, Lenny Dale; cantores: Chico Buarque, Caetano Veloso, Maria Betânia, Elza Soares, Ney Matogrosso, Hermeto Paschoal, Clementina de Jesus; intelectuais: Antonio Cândido, Gilda Mello e Souza, Câmara Cascudo, Gilberto Freyre, Jorge Amado, Clarice Lispector, Jorge Andrade, Henfil, Darcy Ribeiro, Augusto e Haroldo de Campos, Carlos Drummond de Andrade, Lygia Fagundes Telles, Millôr Fernandes; personalidades: Pelé, Lula, Jânio Quadros, Mãe Meninha do Gantois, Irmã Dulce, Joãosinho Trinta, Dom Helder Câmara, Pietro Maria Bardi, José Mindlin, Oscar Niemeyer, Orlando Villas-Bôas; artistas: Di Cavalcanti, Alfredo Volpi, Caribé, Tomie Otake, Hélio Oiticica, Ademir de Barros, Manabu Mabe, Maria Bonomi, Emanoel Araújo. 
MS especializa-se em fotografar as expressões faciais e as roupas dos travestis e transformistas que, na maioria das vezes, posavam em um estúdio improvisado em seu apartamento. Essa busca genuína por rostos é também marcante em duas séries de fotografias que MS produz quando empreende duas viagens (1974 e 1982) para a região Norte e Nordeste do Brasil, dando-nos a ver um material fotoetnográfico que nos ajuda a compreender sua fotografia e a essência do seu fotografar. Em 1974, faz sua primeira exposição individual no Masp sob os auspícios de Pietro Maria Bardi. Continua fotografando para as mais variadas revistas, como Planeta, Status, Lui, Vogue. Na década de 1980, deixa de fotografar regularmente para as revistas e ressente-se de não ser mais chamada para a realização de portraits, o que Brandão apresenta como um dos motivos por que passou a se dedicar à escultura9. Entre 1979 e 1991 trabal ha para a Rede Clobo como fotógrafa contratada, produzindo material de arquivo e portraits de artistas. MS falece em 1993, aos 72 anos, deixando um acervo composto por mais de 16 mil negativos em preto e branco e 450 cromos, que foram adquiridos em 1998 pelo Instituto Moreira Salles.

Embora tenha assumido a fotografia como prática aos 45 anos, quando, em 1966, ingressa no Foto Cine Club Bandeirante seu modo de enquadrar o mundo por meio de faces, rostos, expressões já estava posto, desde sempre, uma vez que o 'pensar por fotografia' não coincide, necessariamente, com o ato mecânico dos obturadores das máquinas fotográficas. Seu filho Jorge Schwartz (2012: 7) destaca sua introspecção e sua capacidade de observação como motores e ordenadores de seu olhar. Esse enquadramento do ol har é destacado por inúmeros fotógrafos como um modo de operar e produzir um olhar sobre o mundo (Hammond, 1920: 71; Freund 1980: 64, 80; Penn, 1977). Uma vez que o retrato é por definição uma composição, depende, sobretudo, de uma capacidade de observação por meio da qual se produz um conhecimento sobre o retratado a partir de escolhas, seleções que transformam a relação entre dois seres humanos em fotografia.

O retrato pode ser, assim, comparado ao gênero lírico ao propor uma fusão entre o eu e o mundo (cf. Araujo, 2006: 235). Essa capacidade de figuração, a criação da figura retratada que manifesta simultaneamente a incorporação de uma individualidade e de uma "culturalidade", é o que os retratos de MS almejam.

\section{CONHECENDO COM UMA CÂMERA: FIXANDO E NÃO FIXANDO IMAGENS}

Beck (1907: 168) afirma, ainda nos primórdios da fotografia, que os fotógrafos treinavam a si mesmos por meio da observação em seus mínimos detalhes e, por isso, desenvolviam uma grande capacidade de captar a personalidade dos retratados.
9 Não encontramos nenhuma imagem ou referência sobre as esculturas de MS que nos permitisse aprofundar a relação entre sua fotografia e sua escultura. 
Uma vez estabelecida a importância da observação na composição do retrato, como um aprofundamento do ol har, um descobrir apreendendo (aprendendo sobre) o sujeito retratado, é preciso enfatizar que este aprendizado se realiza através de uma máquina que medeia a relação entre fotógrafo e fotografado. Tomo aqui a formulação inteligência de uma máquina, proposta por Epstein (1983), como condição da composição do retrato e do modo de sua apreensão. A máquina, "dotada de subjetividade própria", não reproduz simplesmente o que o olho humano vê mas, ao contrário, produz uma espécie de "fantasma" de deslocamento que engendra um estranhar; ao impregnar as imagens, é possível conhecê-las de um modo novo e, assim, "dar um passo em direção ao terrível oculto das coisas" (Epstein, 1983: 288).

MS parecia exercitar conscientemente esse modo de conhecer com uma máquina, em que aliava observação à experiência do ato fotográfico propriamente dito ressaltando a importância da máquina na sua compreensão/composição do retratado. Esse método de conhecer empreendido por MS é apresentado na informação dada por seu filho Jorge Schwartz (comunicação pessoal) e confirmado pela sequência de making off de MS em ação, produzida pela fotógrafa Conceição Almeida, quando fotografava Hermeto Paschoal.

Jorge Schwartz informa que era comum MS iniciar uma sessão de fotos sem colocar filme na máquina. Com a máquina sem filme, gastava rolos e rolos imaginários produzindo uma verdadeira performance de sessão fotográfica. Complementa, dizendo que "às vezes clicava quatro rolos de 36 fotos imaginárias diante do fotografado antes de colocar o primeiro filme real na máquina". Aqui, evidenciamos três questões que nos remetem a este ato de conhecer empreendido por ms. A primeira é a de juntar observação e ato fotográfico. Através da máquina, literalmente, compõe, por meio de seu olhar enquadrado pela lente, o retrato ao procurar conhecer o retratado por fotos imaginárias, experimentando ângulos, enquadramentos em que esquadrinha o entorno e o rosto do retratado. A segunda questão deriva diretamente da relação entre fotógrafa e fotografado. Seu filho diz que a performance produzida por MS a partir dos filmes imaginários era um modo de se aproximar do retratado, de estabelecer uma relação mediada pela máquina. A terceira questão trata da importância atribuída à sequência na composição do retrato. O retrato, longe de ser um fotograma único ou um instante decisivo, é, sobretudo, construído por meio de uma sequência. Assim, quando extraído de uma sequência, condensa de uma só vez a observação, a experiência e a relação: os três pilares da composição do retrato proposto por Ms. A importância da sequência para a compreensão da obra fotográfica de MS é capital, uma vez que a sequência não é composta, somente, dos fotogramas que existem em seu arquivo depois de revelado o filme, mas de todas as fotografias reais e imaginárias que compõem a sequência produzida na sessão 
fotográfica. Ao vermos uma sequência materializada em forma de contato organizado numericamente de filmes revelados a partir da sessão de fotografias do músico e compositor Hermeto Paschoal, deparamo-nos com 18 fotogramas que enquadram apenas seu rosto enquanto toca sax ${ }^{10}$. Entretanto, sabemos que esses 18 fotogramas de Hermeto podem não ser a totalidade das fotos produzidas, uma vez que é necessário incluir como parte constitutiva da sequência de Hermeto as fotos clicadas (não fixadas em filme) na performance de MS através de seus rolos de filmes imaginários.

Essa sessão fotográfica em que MS produz a sequência sobre Hermeto Paschoal foi um dos raros momentos em que podemos acompanhar o making offde sua prática fotográfica, vendo MS em ação, fotografada pela fotógrafa Conceição Almeida"1 , o que ajuda a aclarar seu método de produzir conhecimento. Existem apenas oito fotos em que MS surge de costas, ajoelhada, curvada, mudando de ângulo em múltiplas tomadas, realizando sua performance diante de Hermeto, num jogo de corpo que engendra um diálogo silencioso de olhares, gestos e atenções. Observando as fotos do making offe as 18 fotos da sequência de Hermeto, percebe-se que a fotógrafa produziu muitas fotos não fixadas de Hermeto, isto é, nem todos os enquadramentos do making off coincidem com as fotos fixadas nos negativos contidos na sequência de Hermeto.

Essa concepção de sequência produzida no ato de fotografar engendrando o conhecimento/composição de MS sobre o retratado coloca-nos o problema da fotografia, uma vez que a concepção de MS quer ultrapassar a materialidade do negativo ou do fotograma impresso em papel. Na verdade, as sequências produzidas de imagens não fixadas não apontam uma inexistência de imagens, mas, antes, a presença de uma imagem sem condensação físico-química. Assim, a fotografia de MS acentua o problema da imagem fotográfica ao tratar imagem como experiência, conhecimento e não apenas visualidade fixada-modo de proceder que acentua uma concepção de imagem como produto da observação derivada de uma relação. Essa concepção reverbera diretamente o conceito de corpothetics (Pinney, 2004) enquanto fusão da imagem e do observador, ao acionar uma percepção sensorial em que o importante não é simplesmente o retrato mas também a sequência que o engendra. Assim, o efeito de sequência, pela densidade de sua produção, é que possibilita fazer emergir o portrait enquanto composto, literalmente, pelas imagens fixadas e não fixadas.

\section{FOTOGRAFANDO RELAÇÕES, PRODUZINDO RETRATOS}

Dorothea Lange, em suas reflexões sobre o ato de produzir retratos, acentua que, antes de as fotografias serem disparadas, é preciso que algumas decisões sejam tomadas: a primeira pelo retratado, que decide sobre o que ele dará para
10 Uma dessas fotos transforma-se em retrato e surge em Personae (1997: 66).

11 Estas fotos fazem parte, também, do acervo do IMS. 
a câmera, e depois a do fotógrafo, que decide o que vai receber e escolher do retratado (Acker, 2004: 48). Lange nos fala do retrato como produto da intercessão do que o fotografado dá e do que o fotógrafo toma, trata-se de uma relação e, como qualquer relação, está orientada pela reciprocidade.

Bourdieu (2006: 38) acentuou a importância da reciprocidade como constitutiva do ato fotográfico, ato produtor do retrato: o retratado controla sua imagem e o fotógrafo produz determinado enquadramento. A ideia de "doar a própria imagem" torna-se a essência do ato fotográfico. MS sabia que era preciso pôr em prática determinados dispositivos que permitiriam engendrar o retrato enquanto reciprocidade. Se a mise-en-scène criada por MS para produzir esse momento de reciprocidade é marcada pela construção processual do retrato, as sequências, é também derivada daquilo que surpreende, do instante que produz o retrato. Para MS, o instantâneo, o acidental é valorizado como dispositivo para criar a "pose", produto direto da relação recíproca entre fotógrafa e fotografado.

Ertem (2006) avança a reflexão sobre a pose e o gesto ao analisar os primeiros retratos fotográficos. A pose é testemunha do encontro ou o modo com que um sujeito responde à presença implicada de um observador. É a própria consciência da observação que leva o retratado a assumir uma espécie de "eu imaginado" diante de um outro que estimula esta encenação de si mesmo. Esse sentido de pose como encenação, a produção do gesto enquanto performance, é o que o retrato de MS ambiciona, querendo nos dar a ver uma personalidade, um sentimento, um estado da mente do retratado.

Menezes (2000: 33), explorando o sentido de fotografia em Blow up, filme de Antonioni, acentua a questão do ampliar e do explodir que vai de encontro às definições triviais de imagem fotográfica. Ponto de inversão de significado entre o retrato e a fotografia: no retrato, mede-se o modelo pela foto, uma vez que encarna a ambiguidade da encenação, do ser para outrem, e depende de uma relação entre humanos que ultrapassa a artificialidade da máquina.

A composição do retrato de Di Cavalcanti por MS quer dar a ver uma relação: a de Di Cavalcanti com seu modelo, Marina Montini. A máquina de Ms, que parece flagrar uma cena cotidiana, descreve etnograficamente a essência do próprio retrato que Di Cavalcanti compõe, sua relação com Marina Montini. Di Cavalcanti está com um pincel na mão, em pleno ato criativo, contemplando Marina e a fotógrafa. Marina aparece de perfil, sentada em uma cadeira, posando para Di Cavalcanti e para Ms, olhando para um ponto fixo ao longe. Na mesa do pintor vê-se pincéis e tintas, misturas, potes e Di Cavalcanti sentado diante de seu cavalete observando Marina. Um retrato que compõe o instante criador de seu trabalho: Marina está sentada em uma cadeira de braço, com as pernas cruzadas, deixando aparecer suas coxas através de um recorte na bata africana que veste; vemos seus colares, seu cabelo preso. Neste momento, MS parece 
mimetizar Di Cavalcanti tomando seu próprio olhar ao se inspirar, também, em Marina Montini como modelo, expressando, assim, o olhar de Di Cavalcanti sobre Marina através de sua câmera. Nesse processo, pode-se imaginar, a partir do enquadramento de Marina por MS, o que estaria pintado na tela que não está visível, senão para Di Cavalcanti. O fotograma seguinte nessa sequência mostra duas telas em dois cavaletes que Di Cavalcanti tem à sua frente. Di Cavalcanti está em movimento, de perfil, pintando o quadro, retocando. Um ângulo que, ao enquadrar Di Cavalcanti de cima para baixo com seus dois quadros em segundo plano, transforma, agora, Marina Montini em "retrato" de seu próprio retrato pintado por Di Cavalcanti.

O momento decisivo para MS não é algo capturado ao acaso, mas o que evidencia a relação que se configura entre a fotógrafa e o fotografado produzindo o retrato. Essa forma de fotografar põe em relevo uma série de detalhes não menos importantes na composição do retrato. Não é propriamente o retratado que oferece um gesto encenado ou um ângulo de seu rosto. O retrato é, ele mesmo, produto de uma relação que se impõe como condição mesma desse modo de operação da fotografia. É essa relação que revelaria a "alma" do retratado, concebida como a infraestrutura do retrato, responsável por sua composição, por sua aparição, pela transformação de um rosto em uma expressão, de um fotograma em um retrato.

A máquina de MS procura conhecer, aproximar-se até chegar a um retrato que nada mais é que a própria construção de uma relação estabelecida naquele momento e naquele local, relação que é, ela mesma, testemunha de um encontro. Seus retratos são antes de tudo construções relacionais, como evidenciam suas sequências de fotogramas de Jorge Amado. No fotograma escolhido para representá-lo no livro Personae, Jorge Amado surge com seu cachorro: em primeiro plano, o cachorro de perfil com a língua de fora, em segundo, Jorge Amado contemplativo, um pequeno gesto no rosto acentua as rugas próximas aos olhos. Na sequência das fotos de Jorge Amado, vê-se fotos que vão se aproximando do contexto do fotografado: a primeira foto é a de Jorge Amado de frente, com seu cachorro, de um lado, e sua esposa, Zélia Gatai, de outro. A sequência de fotos procura conhecer o ambiente, aproxima-se em passos progressivos de um enquadramento do que viria a ser o retrato de Jorge Amado.

Com Nelson Lerner, observa-se a mesma conversação com ms: ele está sentado, de corpo inteiro, com roupa preta em um cenário de demolição, depois aparece em close olhando para a câmera, com a mão direita apoiada em seu rosto, em sequência, ele aparece com a mão direita na testa, deixando ver sua enorme barba, também em close. Finalmente, surge seu rosto centrado e em close. São muitos ângulos tomados, todas as possibilidades de ser Nelson Lerner, sua fabulação sobre si. 
O fotografado está consciente da fotografia e parece ser esta a questão que funda a composição do retrato de Ms. Uma menina lava roupa no rio, um rio do Norte ou Nordeste. No segundo plano, vê-se as costas de uma mulher mais veIha, que também lava roupa. A foto descreve uma atividade coletiva, lavar roupa em cima de tábuas na beira do rio. A menina, sorrindo, olha para a câmera, percebendo o ato fotográfico, autorizando, participando com este simples gesto na composição de seu retrato, dando a ver seu cotidiano, sua intimidade.

O retrato é produto dessa cumplicidade entre fotógrafo e fotografado. O que diferencia uma foto de um rosto, de um perfil, de uma pessoa, da composição do retrato é justamente essa consciência do ato fotográfico, que implica colaboração, participação, relação. A mesma colaboração pode ser percebida nas fotos de crianças do Nordeste que olham para a câmera, do menino que espera com seus caranguejos o momento da fotografia, do menino na rede que deixa-se fotografar. Um vendedor de manga mostra sua mercadoria, uma atividade do fotografado na composição de seu retrato. Observa-se a mesma colaboração na sequência de 72 fotos de Henfil, que passa a representar a si mesmo, fazendo as mais diversas poses e caretas, participando ativamente na composição de seu retrato ao declarar por meio de seus gestos o aceite da relação com MS.

Na série os transformistas, de 1975, a pose, o teatral acentuam a colaboração do fotografado, o que se caracteriza como a ontologia do retrato de Ms. O que importa não é quem é fotografado, se personalidades do mundo intelectual, das artes, da política ou negros do Rio Grande do Norte, transformistas de São Paulo. Sua fotografia não busca por rostos, faces, cenas, mas por uma relação que produza o retrato, como composição de uma singularidade do ser encarnado em um corpo ou uma face que expresse, no microcosmos, seu mundo. Nesse sentido, a encenação do "eu" detonada pela relação entre fotógrafo e fotografado dá-nos a ver a verdadeira construção de uma personagem. Daí o trânsito natural, nos retratos produzidos por Ms, do teatro, da encenação, para as personalidades, pessoas anônimas, uma vez que o crucial na composição do retrato é justamente captar essa fabulação sobre si, a criação de um 'eu' que emerge a partir de uma relação. É na relação entre a fotógrafa e o fotografado que se engendra o personagem, essa capacidade de poder se revelar a outrem, de devir retrato, trânsito incessante entre a ficção e a realidade, a encenação da vida e a vida enquanto encenação, o particular e o geral, o singular e o mundo, o individual e o cultural. O retrato seria, por assim dizer, um dispositivo, uma technology of embodiment que produz essa forma de encorporação subjetiva do self transmutado em outro na materialidade da fotografia (Jones, 2002: 950).

A pose é a composição da foto e não a torna mais artificial, pelo contrário, a pose sintetiza os gestos, a performance, dando a ver a fabulação do ser, único modo de se apreender o "eu", que é por meio de sua narração e constituição 
de um personagem na relação com outrem, o que Deleuze (2005) sintetizava enquanto as possibilidades de fabulação do eu como o poder de revelar a constituição do ser, a "potência do falso". Nesse sentido, não existem anônimos na fotografia de MS, o que existem são retratados, às vezes nominados e às vezes sem nome, mas jamais anônimos. Os retratos (des)realizam o cotidiano por meio da vida como encenação. Retornamos à questão da performance da vida como vida, da vida como teatro, como pessoa, como personagem e de como as pessoas transformam-se em personagens, na encenação da vida, numa palavra, no retrato.

Essa qualidade do retrato produzido por MS amplifica a ideia de tela, da pose enquanto o único modo de termos acesso à imagem de uma pessoa (Jones, 2002: 950). A ideia de tela, screen, provém de um conceito de Lacan (1981: 107 apud Jones, 2002: 957), em que ele elabora tela como o sentido do retrato, como locus da mediação em que o sujeito "mapeia-se na captura imaginária do olhar" e, desse modo, o sujeito, portanto, é sempre foto-grafado, uma vez que é objeto e sujeito do olhar, produto dessa intermediação da tela que produz o eu e o outro, o objetivo e o subjetivo. Na tela como retrato, Lacan (1981: 107) reconhece explicitamente sua natureza de duplo, de máscara, de segunda pele (Jones, 2002: 958). Assim, o retrato não pode ser tomado como uma forma bidimensional da tela. É mediação e, por esse caráter, revela a profundidade e a materialidade de uma relação (cf. Jones, 2002: 970).

É o que se observa nos retratos de ms, seja o de um cordelista em Salvador em plena execução do cordel, o de um vendedor de caranguejos, o de personagens de teatro, de transformistas, de Ney Matogrosso: vê-se o gesto, o movimento, a cena e a encenação da vida como constituintes e instituintes do retrato. Essa capacidade de pensar o retrato como performance parece derivar de uma percepção de Ms, exposta em seu imaginário imagético, que é a plena consciência e reconhecimento da potência que resulta de uma relação estabelecida por meio de uma câmera, momento profundo de reflexão que instaura o retrato que é a construção, possibilidade de fabulação, de um modo de ser 'eu' na relação com um outro.

\section{SEQUÊNCIAS: QUANDO UM FOTOGRAMA VIRA RETRATO OU O X DA QUESTÃO}

O problema da sequência encontra toda a sua plenitude no modo como Andy Warhol elaborava seus retratos, o que nos permite compreender o portrait enquanto produção paradoxal de um compósito de singularidade e universalidade, de interioridade e exterioridade, derivado das concepções de composição, fabricação, fabulação, invenção. A descrição de Pat Hackett na introdução aos Diários de Andy Warhol nos dá essa dimensão: 
O processo de Andy ao fazer um retrato era complicado. Começava com a pessoa posando para que ele tirasse aproximadamente sessenta fotos polaroides. Depois dessas sessenta fotos ele escolhia quatro e passava para o impressor de tela para obter imagens em positivo em acetatos de $20 \times 25 \mathrm{~cm}$. Quando os acetatos voltavam para ele, escolhia uma imagem, decidia como cortá-la e aí começava a retocá-la cosmeticamente para fazer com que a pessoa parecesse o mais atraente possivel -alongava pescoços, afinava narizes, aumentava lábios e esmaecia peles como achava que fosse necessário. Então a imagem retocada de $20 \times 25 \mathrm{~cm}$ era ampliada para um aceta to de $1 \times 1 \mathrm{~m}$, do qual o impressor fazia a gravura [...] (Hackett, 2012:19)

O retrato é pensado, muitas vezes, enquanto imagem congelada, única, do retratado. Mas o retrato é proveniente de um fluxo de imagens, das sequências fotográficas, da relação entre fotógrafo e fotografado, de escolhas que envolvem múltiplos níveis de abstração, prática e conceituação. Por essa razão muitos fotógrafos não autorizam a publicação de sequências de suas fotos, uma vez que poderiam ressignificar a relação entre fotógrafo e fotografado condensada na escolha daquele fotograma que se transformou em retrato. Robert Frank, por exemplo, jamais autorizou a publicação de suas sequências, pois não queria revelar seu método de trabalho ${ }^{12}$; tal publicação poderia induzir, a uma percepção de que a edição foi produzida tão somente pelo próprio fotógrafo, que teria total controle sobre a representação do fotografado. Wolfeson (2009: 13), a partir de seu trabalho sobre as fotos de Otto Stupakoff, intitulado provocativamente Sequências, demonstra que a visualização dos fotogramas que não foram escolhidos pelo fotógrafo permite outras interpretações sobre sua obra fotográfica.

A sequência é, nesse sentido, a busca do retrato, uma entrada no mundo do fotografado ao apresentar fotos que narram, por meio de objetos e pessoas, um segundo plano que força uma compreensão da pessoa fotografada, imagetificando o seu papel social. Assim, as sequências produzidas por MS descrevem atos criativos, os quais cercam seus fotografados, revelando contextos que produzem uma fusão entre a pessoa e o personagem, no sentido pleno de realização do papel social de seu fotografado.

A sequência do ator Paulo Vilaça, composta por 55 fotogramas, permite observar mais claramente o método de MS em extrair, da sequência, o retrato de Paulo Vilaça que sintetizaria aquele encontro materializado em todos aqueles contatos, em que o ator aparece numa clara encenação, em muitas poses com uma arma na mão. Atrás do primeiro contato está escrito: "18×24, não fazer as que tem cruz". Das 55 fotos, 44 estão assinaladas com uma cruz feita em lápis hidrocor rosa. Nesse caso, utiliza o método de eliminação para chegar às 11 fotos e, dessas 11, vê-se, em apenas duas fotos, uma marca feita a caneta
12 Optamos deliberadamente por não apresentar nenhuma sequência fotográfica de MS por questões éticas que envolvem a exposição de fotogramas não autorizados explicitamente pela autora. 
esferográfica azul de um pequeno $x$ no alto do canto esquerdo do fotograma: uma foto de corpo inteiro de Paulo, que está de frente com o revólver na mão, e outra de perfil, cortada na altura dos joelhos. Se esse pequeno $x$ azul representa uma escolha de Ms, pode-se intuir que escolheu claramente as fotos mais contidas, menos posadas de toda a série, o que confirma que, mesmo no caso das poses deliberadas por ela ou pelos fotografados, mesmo nas fotos de peças teatrais, ela quer revelar com o retrato uma relação, o momento que mais condensa o encontro.

Uma vez que o retrato é produzido num processo determinado pelo $x$ azul que acrescenta e pelo $x$ em rosa que exclui, vejamos outras sequências e o que nos informam sobre o seu método.

A sequência do artista e editor Massao Ohno ilustra de forma contundente o modo de operar de MS na construção de sua relação com o fotografado de modo a produzir o retrato. São 68 fotogramas que começam e terminam com Massao Ohno sentado em uma cadeira, sempre com sua filha ao redor. Sua filha está ao seu lado e participa como coadjuvante de inúmeros fotogramas, circula em seu entorno ao seu redor, beijando-o, brincando. Sua filha transforma-se em personagem e conquista uma relação com Ms, que a fotografa posando para a câmera sentada em uma almofada, com um chapéu de plumas, enquadrada pela moldura da janela olhando para fora, até assumir o lugar do pai em uma cadeira. Riem juntos, divertem-se com a encenação e MS vai se aproximando, fotografando, buscando extrair dali o que seria Massao Ohno. Em seguida, vemos mais fotogramas que produzem uma sequência que quase gera uma imagem em movimento de Massao, apresentando alguns perfis e procurando, incessantemente, nesse jogo de aproximação e distância, incluir e excluir os elementos do contexto para produzir o retrato de Massao Ohno. Restam mais três fotogramas de Massao enquadrado em close, fumando. Chega-se a uma síntese do que seria Massao Ohno nessa sessão de fotos com Ms. O retrato de Massao retira o contexto apenas do fotograma, não da relação estabelecida para a sua produção.

O que é interessante pensar a partir das sequências de fotos é como e de que modo um fotograma se transforma em retrato. Em que momento o retrato coincide com o fotografado, querendo dar a ver uma expressão para além de um rosto que o abriga e que é produzido por essa expressão? Seria algo simplesmente arbitrário, ditado por uma interpretação subjetiva do fotógrafo ou do editor do livro, ou tal transformação do fotograma em retrato exprime essa complexidade da relação colaborativa e participativa entre fotógrafo e fotografado?

O retrato de Antonio Cândido foi escolhido dentre os 47 fotogramas que compõem a sua sequência. Na maioria das fotos, Antonio Cândido aparece pouco à vontade, atrás ou na frente de Gilda, sua esposa, sentado em uma poltrona, olhando para a câmera seriamente, produzindo fotos posadas com um olhar cir- 
cunspecto. Existem apenas sete fotos em que esboça um sorriso, até surgir uma foto em que sorri francamente para a fotógrafa: seus óculos estão sobre a mesa, veste uma camisa de gola rolê e um blazer tweed, vê-se sua aliança, seu relógio e, num segundo plano, livros de capa dura encadernados com lombadas grossas provavelmente douradas, reluzentes na foto. Apoia uma das mãos na mesa e a outra, sobre a perna direita. Essa foto seria do segundo filme, a número 7, de uma subsequência que começa na número 3 e vai em crescendo até a sétima foto, que captura a "essência" de Antonio Cândido. Somente depois de 40 fotos é que surge um Antonio Cândido receptivo, colaborativo, parceiro.

As fotos de Câmara Cascudo, em contraste com as de Antonio Cândido, descrevem mais seu cotidiano, mostram seu ambiente de trabalho, sua casa, seu escritório. Seu retrato é composto como se Câmara Cascudo estivesse trabalhando, fumando charuto em sua cadeira-poltrona, lendo livros. Vê-se, em segundo plano, sua impressionante biblioteca. Surgem outras fotos em que aparece acompanhado de sua esposa, ora ao seu lado, ora atrás de sua cadeira. As fotos de contexto aproximam o espectador de seu mundo: livros, objetos de arte popular, ele sentado atrás de sua mesa. Uma subsequência (cinco fotos) o enquadra em close no momento em que coloca seus óculos. O filme inicia enquadrando seu escritório para, em seguida, aproximar a lente do fotografado, que passa a ocupar todo o quadro. Ao final do filme MS retorna para as fotos de contexto, dos objetos, da cena de seu escritório. MS parecia realizar, com esse vai e vem do contexto ao texto, do segundo ao primeiro plano, um exercício de conhecimento do ambiente, deixando-nos ver claramente que não era apenas e tão somente o retratado, ou seu rosto, que a interessava.

Observa-se o mesmo procedimento na sequência de 34 fotos da filósofa Marilena Chauí. Todas as fotos, sem exceção, estão enquadradas com um segundo plano que produz essa segunda camada de significação, não menos importante que a primeira, a qual está centrada na pessoa, em sua face, em seu gestual, em sua corporalidade. As fotos fazem surgir Marilena e o que está atrás dela: nas paredes, alguns posters, estantes de livros. Em uma longa sequência de 28 fotos, Marilena é fotografada de múltiplos ângulos junto a seu objeto mais precioso: uma enorme máquina de escrever elétrica. Em apenas duas dessas fotos surge sem olhar diretamente para a câmera, para ms: nelas, está em ação, escrevendo, datilografando. A máquina de escrever toma de assalto a cena, sendo a partir daquele momento a protagonista da sequência, colocando-se no lugar de Marilena, de seu conhecimento, de seu saber. Percebe-se, claramente, que a máquina de datilografar ocupa um espaço importante na composição do seu retrato, numa apreensão metonímica que intensifica a apreensão desse regime imagético, a parte pelo todo, a máquina por Marilena.

As 32 fotos de Gilberto Freyre são tomadas no mesmo contexto. Sentado 
diante de uma mesa, posando para a câmera, de perfil, e, depois, duas fotos ao lado de uma mulher (provavelmente sua esposa), ambos sentados em cadeiras no mesmo ambiente. $O$ fotograma que vira seu retrato é justamente uma aproximação súbita da câmera que enquadra todo o seu rosto de perfil. Percebe-se que há muito mais fotos de contexto do que closes de Freyre nesta sequência. Há, ainda, uma curiosa fotomontagem encontrada nesta coleção que, embora não se saiba se foi produzida por ms, é de todo modo muito significativa por colocar em prática uma montagem, intensificando a relação entre o contexto e o retratado, produzindo uma composição da imagem. A fotomontagem é a seguinte: 0 rosto de Gilberto Freyre ocupa todo o lado direito da foto, como uma espécie de incrustação de seu rosto em uma antiga iconografia em que se vê uma cena de escravos, sentados diante de uma casa-grande realizando atividades cotidianas, como trançar um tapete de palha, com seus filhos. Da sacada da casa-grande vê-se uma mulher branca, uma sinhá, que observa a cena, do mesmo modo que Gilberto Freyre observa toda a cena da casa-grande e da senzala.

As sequências do Nordeste, na sua grande maioria, são fotos de casas, famílias, reuniões, ensaios de música em que os rostos vão surgindo aqui e ali. A composição do retrato parece exigir de MS esse método de aproximação do contexto, demonstrando seu interesse genuíno em compreender o que fotografava: um método de pesquisa, em que a composição do retrato parece ser uma consequência que advém de seu estudo do contexto. Assim, vê-se meninos que pulam na água, uma menina que lava roupa, uma praça vazia, a estátua da praça, uma casa, crianças brincando, cortando melancias, batendo tambor e, na sequência, vão surgindo os rostos, os enquadramentos mais corporais fixados em faces. Observa-se cinco fotogramas em sequência do rosto de uma menina. A próxima foto apresenta o interior de uma casa e a família que a habita. Observa-se o mesmo movimento de fotos: a casa, a cozinha, a família na sala e, daí, surgem mais quatro fotos em sequência de um rosto de um rapaz. Em seguida retorna, novamente, para as cenas da casa e das redes, chega-se ao exterior da casa e, aí, vê-se mais uma sequência de rostos em close de uma menina. Vemos, assim, o seu método de conhecimento, seu modo de produzir para si mesma uma linguagem imagética através de sua lente, que procura compreender onde está, quem é a pessoa a ser retratada, aprofundar o segundo plano para enquadrar o primeiro, de modo a derivar o segundo por exercício de imaginação.

Nessa mesma viagem ao Nordeste, fotografa 12 vezes em sequência o rosto de um senhor negro de barba branca. No seu exercício de fotografar, procurava com a sequência das fotos uma forma deliberada de captar não apenas um rosto e, assim, empreende um método de aproximação e afastamento do rosto, do plano e do contexto, o que revela sua intenção de produzir, com as fotos de contexto, uma espécie de segunda camada que permite, através do rosto, situar 
imaginariamente onde esta face e este corpo se situam, o contexto social que enquadra o retrato. As fotos que sucedem e antecedem o rosto do homem negro de barba são fotos do povoado, casarões, igrejas, pessoas arando a terra, crianças pegando água numa bica. Essa dimensão nos reenvia para aquilo que seria o misterioso do retrato, os fotogramas que não vemos, o que está na sequência mas não, por isso, menos importante para produzir uma capacidade imaginativa através de um rosto ou uma expressão.

O mesmo método se desdobra nas fotos da festa de lemanjá em Santos: grupos de pessoas reunidas em roda na areia da praia, pessoas dançando e cantando, velas brancas na areia fotografadas de variados ângulos. Desta sequência, vão surgindo personagens: uma subsequência de cinco fotos de uma senhora portando muitos colares e um turbante, com velas nas mãos; a última foto apresenta a mesma senhora depositando as velas na areia, a oferenda. Surge um close de um menino que toca um tambor. Uma foto da senhora, de corpo inteiro, com várias saias, empunhando as velas acesas (esta é a que se transformou em retrato), permite-nos ver o contexto da praia lotada de adeptos das religiões afro-brasileiras, atabaques, homens e mulheres com suas roupas características.

Na sequência dos irmãos Campos observa-se que, na maioria das fotos, são fotografados juntos, no mesmo ambiente. Surgem perfis, closes de Haroldo, closes de Augusto e, em seguida, seguem fotos com seus familiares, filhos, os quais vão compondo as fotos com os dois e, inclusive, tornam-se, sozinhos, os retratados. Percebe-se que o enquadramento de um rosto é um momento numa longa série de 97 fotos que ajuda a compor o retrato de Augusto e Haroldo de Campos: da sala da família, dos quadros na parede, junto ao piano, sentados no sofá com seus familiares. Dos 97 fotogramas, 22 são exclusivamente de sua família. Dessa forma, MS associa a produção do retrato à condição particular de entrar na intimidade de seu retratado, no sentido de apreender não apenas suas próprias expressões e closes, mas também as de sua casa, sua família, , como condição de poder apreender seu mundo, seu universo por meio de seu retrato. Assim, deve-se pensar que o retrato é um processo vivido nas sequências que instauram essa relação delicada entre MS e seus fotografados.

O método de fotografar de MS, derivado de seus contatos e sequências, institui-se a partir dessas inversões frequentes entre pessoas que emolduram contextos e contextos que emolduram pessoas. Percebe-se na sequência das fotos uma intromissão deliberada de MS de produzir o que seria o subjetivo no ato de fotografar, uma espécie de desvio do ol har do personagem a ser retratado para o seu entorno. Longe de isolar o fotografado em um quadro fora de seu contexto, parece que deseja que o olhar da câmera não fique somente focado na pessoa a ser retratada e, por isso, inclui o ambiente e as pessoas que estão em torno do fotografado. Inclui, em geral, pessoas íntimas dos fotografados, filhos, 
esposas, maridos, amigos: Hebe Camargo aparece em uma longa sequência de 32 fotos com o seu filho; Calazans Neto, em seu ateliê com sua esposa; Sérgio Buarque, com seu filho Chico; Massao Ohno, com sua filha; e isso se multiplica com cachorros, gatos, objetos, charutos, cigarros, roupas, quadros, móveis, casas.

\section{ETNORRETRATO: O ATO FOTOGRÁFICO COMO ATO ETNOGRÁFICO}

O etnográfico no retrato de MS é menos temático-como suas fotografias produzidas nas viagens que realiza ao Nordeste e ao Norte do Brasil, que vieram a se tornar as sequências de retratos do "povo brasileiro" - e mais epistemológico, no sentido em que ajuda a produzir um conhecimento sobre o retratado. A composição de seu retrato leva em conta, fortemente, um segundo plano como forma de sua composição, seja em um retrato de Carlos Drummond de Andrade, de Irmã Dulce ou aqueles produzidos em suas viagens. Pode-se dizer que mais de $70 \%$ dos portraits apresentam essa relação entre o plano do fotografado e uma composição do entorno. Primeiro e segundo plano condensam, em sua fotografia, o ato fotográfico e o ato etnográfico, que caminham juntos na produção do retrato, revelando, literalmente, a dimensão pessoal de estar situado em um mundo, o que pode ser definido como o aspecto cultural encorporado do retratado. $\mathrm{O}$ conceito de etnorretrato parece adequado a esse tipo de composição quando se leva em conta a importância das sequências, a experiência do ato fotográfico e a relação criada entre fotógrafa e fotografado.

Assim, uma simples visualização dos retratos sugere que o segundo plano é de suma importância na composição proposta por ms, seja um segundo plano visível no próprio retrato, seja aquele que surge com mais evidência nas sequências. Trata-se de um modo de enquadrar que privilegia a descrição, que dá um sentido a uma atuação no mundo, que constrói um cenário, que emoldura o retratado.

A composição do retrato de Carlos Drummond de Andrade atesta essa capacidade de produzir uma etnografia do retratado. Ele está sentado em uma cadeira antiga, olhando para baixo parecendo pensar no mundo. Vê-se, claramente, seu relógio, a fivela de seu cinto, seus óculos, sua camisa social de bolinhas, seu paletó e o braço da cadeira antiga em que está sentado. Atrás dele surgem duas imagens de santos barrocos que enquadram sua cabeça e, ao fundo, vê-se um quadro na parede e nele, o reflexo de MS no momento em que produz a fotografia, atestando literalmente, por meio de sua aparição, sua participação na construção dessa narração do retratado.

MS produziu uma etnografia por meio de gestos, dos detalhes, de expressões. O etnorretrato revela aspectos psicológicos e singulares de uma pessoa, ao mesmo tempo em que busca apontar segundos planos que revelem uma visão de mundo. Isso parece ser o que constitui a essência do olhar de MS e a sua 
busca incessante para demonstrar por meio de suas imagens a não contradição entre a singularidade e a ideia de pertencer a um contexto, a uma cultura, a uma geração, a um momento da história.

Os retratos de MS, seja de personalidades, seja do povo brasileiro, são construídos com o mesmo intuito e a crença de que as pessoas são, únicas e idiossincráticas, mas também encarnações de mundos. Daí a importância do entorno da fotografia: os familiares, as intrusões de pessoas e os objetos que cercam o retratado. $\mathrm{O}$ que parece importante em sua foto e em sua composição do retrato é que tanto o fotografado quanto MS transformavam-se naquele encontro; de modo análogo, o fotograma transforma-se em retrato por meio desse processo. MS inventa-se como fotógrafa para outrem, que se inventa para Ms, para a sua câmera e, por meio dessa relação entre fotógrafa e fotografado, surgem sequências, processos e, consequentemente, retratos.

Marco Antonio Teixeira Gonçalves é Professor do Programa de Pós-Graduação em Sociologia e Antropologia da UfR] e do Departamento de Antropologia Cultural do IFCS-UFR]. É Mestre e Doutor em Antropologia Social pelo Programa Pós-Gradução de Antropologia Social do Museu Nacional-ufrj e realizou Pós-Doutorado na Universidade de St Andrews (1997).

\section{REFERÊNCIAS BIBLIOGRÁFICAS}

ACKER, Kerry

2004 Dorothea Lange. Philadelphia, Chelsea House Publishers.

ANTONIONI, Miguelangelo

1966 Blow-up. Itália/Inglaterra.

ARAUJO, Cicero

2006 "Representação, retrato e drama". Lua Nova, n. 67: 229-260.

BAILEY, David

1984 Face, December. 


\section{BAKER, George}

1996 "Photography between Narrativity and Stasis: August Sander, Degeneration, and the Decay of the Portrait". October, vol. 76: 72-113.

BAXANDALL, Michael

1972 Painting and Experience in Fifteenth Century Italy. Londres, Warburg Institute/ University of London.

BECK, Otto Walter

1907 Art Principles in Portrait Photography. Nova York, The Baker \& Taylor Company Publishers.

BOURDIEU, Pierre e BOURDIEU, Marie-Claire

2006 "O camponês e a fotografia". Revista de Sociologia e Política, Curitiba, vol. 26: 31-39.

BRANDÃO, Ignácio de Loyola

1997 “Apresentação". In Schwartz, M. (org.), Personae.

São Paulo, Companhia das Letras.

BURCKHARDT, Jacob

2000 O retrato na pintura italiana do renascimento. Campinas, Ed. da Unicamp.

BRUSSELE, Michael e WILSON, David

1994 The Perfect Portrait Cuide: How to Photograph People. Sussex, Roto vision.

COSTA, Helouise e SILVA, Renato Rodrigues

2004 A fotografia moderna no Brasil. São Paulo, Cosac Nayfi.

DELEUZE, Gilles

2005 A imagem-tempo. Cinema 2. São Paulo, Brasiliense.

DELEUZE, Gilles e GUATTARI, Félix

[1980] 1987 "Year Zero: Faciality". In A Thousand Plateaus: Capitalism and Schizophrenia. Minneapolis, University of Minnesota Press, pp.167-91.

EDWARDS, Elizabeth

2001 Raw Histories. Photographs, Anthropology and Museum. Oxford, Berg.

2002 "Material Beings: Objecthood and Ethnographic Photographs". Visual Studies, vol. 17, n.1: 67-75. 
2006 Sensible Objects. Colonialism, Museums and Material Culture. Oxford, Berg.

2011 "Tracing Photography". In RUBY, ]. e BANKS, M. (orgs.), Made

to be Seen: Perspectives on the History of Visual Anthropology.

Chicago, University of Chicago Press, pp. 159-189.

2012 "Objects of Affect: Photography Beyond the Image".

Annual Review of Anthropology, vol. 41: 221-34.

EDWARDS, Elizabeth; COSDEN, Chris; e PHILLIPS, Ruth B.

2006 Sensible Objects. Colonialism, Museums and Material Culture. Oxford, Berg.

EPSTEIN, Jean

1983 "A inteligência de uma máquina". In XAVIER, I. (org.), $A$ experiência do cinema. Rio de Janeiro, Graal, pp. 283-287.

ERTEM, Fulya

2006 "The Pose in Early Portrait Photography: Questioning Attempts to Appropriate the Past". Image [\&] Narrative, vol. 14: 76-95.

FABRIS, Ana Teresa

2004 Identidades virtuais. Uma leitura do retrato fotográfico.

Belo Horizonte, Editora da UFMc.

FOUCAULT, Michel

1981 Esto no es una Pipa. Ensayo sobre Magritte. Barcelona, Anagrama.

2000 As Palavras e as Coisas. Uma arqueologia das ciências humanas. São Paulo, Martins Fontes.

FREEDBERG, David

1989 The Power of Images. Studies in the History and Theory of Response. Chicago, The University of Chicago Press.

FREUND, Gisele

1980 Photography \& Society. Boston, David R. Godine Publisher.

GEERTZ, Clifford

1997 "A arte como um sistema cultural". In GEERTZ, C. O saber local. Novos ensaios em antropologia interpretativa. Petrópolis, Editora Vozes. 
HACKETT, Pat

2012 "Introdução". In WARHOL, A. Diários de Andy Warhol (1976-1981). Porto Alegre, L\&PM.

HAMMOND, Arthur

1920 Pictorial Composition in Photography. Boston, American

Photographic Publishing Company.

HARVEY, John

2007 Photography and Spirit. Londres, Reaktion Books.

HEAD, Scott

2009 "Olhares e feitiços em jogo: uma luta dançada entre imagem e texto". In GONÇALVES, M. e HEAD, S. (orgs.), Devires imagéticos. A etnografia, o outro e suas imagens. Rio de Janeiro, 7letras.

HITCHCOCK, Alfred

1954 Janela indiscreta. Estados Unidos.

HOBBES, Thomas

1983 Leviatã ou matéria, forma e poder de um Estado eclesiástico e civil. (Coleção Os Pensadores). São Paulo, Abril Cultural.

HOLME, Charles

1905 Art in Photography. Nova York, Offices of the studio publisher.

JONES, Amelia

2002 “The 'Eternal Return': Self Portrait Photography as a

Technology of Embodiment". Signs, vol. 27, n. 4: 947-978.

KEATING, Patrick

2006 "Studies from the Portrait to the Close-Up: Cender and Technology in Still Photography and Hollywood Cinematography". Cinema Journal, vol. 45, n. 3: 90-108.

KRAUSS, Rosalind

2002 O fotográfico. Barcelona, Editorial Gustavo Gili. 
LACAN, Jaques

[1964] 1981 "What is a Picture?" In The Four Fundamental Concepts of Psycho-Analysis. Nova York, w. w. Norton Editor.

LÉVY-BRUHL, Lucien

1910 Les Fonctions mentales dans les sociétés inférieures. Paris, Alean.

1922 La Mentalité primitive. Paris, Alean.

MASKELL, Henry

1912 Photography. Nova York, Doubleday Page \& Company.

MAUSS, Marcel

2001 Sociologia e antropologia. São Paulo, Cosac Naify.

MENEZES, Paulo

2000 "Blow Up-imagens e miragens". Tempo Social, São Paulo, vol. 12, n. 2: 15-35.

MITCHELL, WIIliam ]. T.

2005 What do Pictures Want? The Lives and Loves of Image.

Chicago, The University of Chicago Press.

MOURA, Flavio e TITAN JR., Samuel

2012 "Uma figura singular". In SCHWARTZ, M., Crisálidas.

São Paulo, Instituto Moreira Salles, pp.8-14.

NEWHALL, Beaumont

2001 The History of Photography from 1839 to the Present.

Nova York, The Museum of Modern Art.

NOVAES, Sylvia Caiuby

2008 "Imagem, magia e imaginação: desafios ao texto antropológico". Mana, vol. 14, n. 2: 455-475.

O'BRIEN, Michael F. e SIBLEY, Norman

1995 The Photographic Eye. Learning to See with a Camera. Worcester, Davis Publications.

PENN, Irvin

1977 "Interview". In JANIS, P. (org.), Photography within the Humanities. New Hampshire, Addison House Publishers. 
PINNEY, Christopher e THOMAS, Nicholas

2001 Beyond Aesthetics. Art and the Technologies of Enchantment. Oxford, Berg.

2004 "Photos of the Cods": The Printed Image and Political

Struggle in India. Londres, Reaktion Books.

SAMAIN, Etienne

2012 "As peles da fotografia: fenômeno, memória/arquivo, desejo". Visualidades, Goiânia, vol.10, n.1:151-164.

SCHNEIDER, Norbert

2002 The Art of the Portrait. Masterpieces of European Portrait

Painting, 1420-1670. Londres, Taschen.

SCHWARTZ, Madalena

1997 Personae. São Paulo, Companhia das Letras.

2012 Crisálidas. São Paulo, Instituto Moreira Salles.

SCHWARTZ, Jorge

2012 "Apresentação" In SchawarTZ, M., Crisálidas.

São Paulo, Instituto Moreira Salles.

SECALA, Lygia

1999 "O retrato, a letra e a história: notas a partir da trajetória social e do enredo biográfico de um fotógrafo oitocentista".

Revista Brasileira de Ciências Sociais, vol. 14, n. 4:159-168.

SOBIESZEK, Robert A.

1999 Chost in the Shell. Photography and the Human Soul, 1850-2000.

Cambridge, MIT Press/Los Angeles County Museum of Art.

TACCA, Fernando de

2005 "Imagem fotográfica: aparelho, reepresentação e significação". Psicologia \& Sociedade, vol. 17, n. 3: 09-17.

TAMINIAUX, Pierre

2009 The Paradox of Photography. Nova York, Rodopi.

TISSANDIER, Gaston

1876 A History and a Handbook of Photography. Londres, Sampson \& Searle Editors. 
WOLFESON, Bob

2009 Sequências: Otto Stupakoff. São Paulo, Instituto Moreira Salles.

\section{Portrait, Self and Image: The Photogra- phic World of Madalena Schwartz}

\section{ABSTRACT}

In this article I analyze the oeuvre of Madalena Schwartz, a Hungarian photographer based in São Paulo since the 1960s, responsible for the creation of a substantial visual archive of Brazil at the end of the 2oth century through portraiture. With her work as a starting point, I explore the meaning of portraiture for the construction of modern imagination and its implications in conceptual discussions about image, physicality, personhood, likeness and individual in anthropology. In my approach to the portraits by Madalena Schwartz I conceptually engage with the phenomenological turn in the study of photography in the social sciences, which privileges the experiential level over the semiotic. The portrait, thus, involves engagement and experience and is constituted through social relations. In this sense, the portrait is taken as a materialization of the relationship between the photographer and the photographed.

\section{KEYWORDS}

Portrait, Photography, Personhood, Image, Individual, Madalena Schwartz.

Recebido em julho de 2016. Aceito em setembro de 2016. 